\title{
Morphological, physiological and behavioural evaluation of a 'Mice in Space' housing system
}

\author{
Dieter Blottner $\cdot$ Najet Serradj $\cdot$ Michele Salanova $\cdot$ Chadi Touma $\cdot$ Rupert Palme $\cdot$ \\ Mitchell Silva · Jean Marie Aerts · Daniel Berckmans - Laurence Vico - Yi Liu · \\ Alessandra Giuliani · Franco Rustichelli $\cdot$ Ranieri Cancedda $\cdot$ Marc Jamon
}

Received: 27 May 2008/Revised: 10 September 2008/Accepted: 12 December 2008/Published online: 8 January 2009

(C) Springer-Verlag 2009

\begin{abstract}
Environmental conditions likely affect physiology and behaviour of mice used for life sciences research on Earth or in Space. Here, we analysed the effects of cage confinement on the weightbearing musculoskeletal system, behaviour and stress of wild-type mice (C57BL/6JRj, $30 \mathrm{~g}$ b.wt., total $n=24$ ) housed for 25 days in a prototypical
\end{abstract}

Communicated by G. Heldmaier.

Electronic supplementary material The online version of this article (doi:10.1007/s00360-008-0330-4) contains supplementary material, which is available to authorized users.

\section{Blottner $(\bowtie) \cdot$ M. Salanova}

Vegetative Anatomy, Center of Space Medicine Berlin, Neuromuscular Group, Charité Universitätsmedizin Berlin, Freie und Humboldt Universität Berlin,

14195 Berlin, Germany

e-mail: dieter.blottner@charite.de

M. Salanova

e-mail: Michele.Salanova@charite.de

N. Serradj · M. Jamon ( $\square)$

INSERM U910-Génomique Fonctionelle Comportements et Pathologies Faculté de Médicine de la Timone,

27 Bd Jean Moulin, 13385 Marseille Cedex 05, France

e-mail:marc.jamon@univmed.fr

N. Serradj

e-mail: Nadjet.Serradj@univmed.fr

\section{Touma}

Max Planck Institute of Psychiatry, Neuroendocrinology, 80804 Munich, Germany

e-mail: touma@mpipsykl.mpg.de

\section{R. Palme}

Biochemistry, Department of Natural Sciences,

University of Veterinary Medicine,

1210 Vienna, Austria

e-mail: Rupert.Palme@vu-wien.ac.at ground-based and fully automated life support habitat device called "Mice in Space" (MIS). Compared with control housing (individually ventilated cages) the MIS mice revealed no significant changes in soleus muscle size and myofiber distribution (type I vs. II) and quality of bone (3-D microarchitecture and mineralisation of calvaria, spine and femur) determined by confocal and micro-computed tomography. Corticosterone metabolism measured non-invasively (faeces) monitored elevated adrenocortical activity at only start of the MIS cage confinement (day 1). Behavioural tests (i.e., grip strength, rotarod, L/D box,

\section{Silva · J. M. Aerts · D. Berckmans}

Faculty of Applied Biosciences and Engineering,

Measure, Model and Manage Bio-Responses (M3-BIORES),

Kasteelpark Arenberg 30, 3001 Heverlee, Belgium

e-mail: Mitchell.Silva@biw.kuleuven.be

D. Berckmans

e-mail: Daniel.Berckmans@biw.kuleuven.be

L. Vico

INSERM U890-Laboratoire de Biologie du Tissu Osseux, IFR143, FRESIS, Saint-Etienne, France

e-mail: Laurence.vico@univ.st-etienne.fr

Y. Liu · R. Cancedda

Department of Oncology, Biology and Genetics,

University of Genova, 16132 Genova, Italy

e-mail: yi.liu@istge.it

R. Cancedda

e-mail: ranieri.cancedda@unige.it

A. Giuliani · F. Rustichelli

Department of Sciences Applied to Complex Systems,

Polytechnic University of Marche, 60131 Ancona, Italy

e-mail: a.guiliani@alisf1.univpm.it

F. Rustichelli

e-mail: f.rustichelli@alisf1.univpm.it 
elevated plus-maze, open field, aggressiveness) performed subsequently revealed only minor changes in motor performance (MIS vs. controls). The MIS habitat will not, on its own, produce major effects that could confound interpretation of data induced by microgravity exposure during spaceflight. Our results may be even more helpful in developing multidisciplinary protocols with adequate scenarios addressing molecular to systems levels using mice of various genetic phenotypes in many laboratories.

Keywords Mouse physiology - Spaceflight . Musculoskeletal system - Stress - Behaviour . Genetically engineered animal models . Animal housing and cage

$\begin{array}{ll}\text { Abbreviations } & \\ \text { ANOVA } & \text { Analysis of variance between groups } \\ \text { Bf } & \text { Bonferroni test (alpha error cumulation) } \\ \text { CM } & \text { Corticosterone metabolite } \\ \text { CSA } & \text { Cross-sectional area } \\ \text { ESA/ESTEC } & \text { European Space Agency/Technical Center } \\ \text { EIA } & \text { Enzyme-linked immunoassay } \\ \text { EPM } & \text { Elevated plus-maze test } \\ \text { HA } & \text { Hydroxylapatite } \\ \text { IVC } & \text { Individually ventilated cage (normal area } \\ & \text { size) } \\ \text { IVCR } & \text { IVC cage with reduced area size } \\ \text { keV } & \text { Kilo electric volts (beam energy) } \\ \text { IR } & \text { Infrared } \\ \text { KWH } & \text { Kruskal-Wallis } H \text { test } \\ \text { L/D box } & \text { Light/darkness box } \\ \mu \text { G } & \text { Microgravity } \\ \text { MIS } & \text { Mice in Space cage device } \\ \text { MSRM } & \text { Mouse science reference module } \\ \text { micro-CT } & \text { Micro-computed tomography (bone } \\ & \text { microstructure analysis) } \\ \text { MWU test } & \text { Mann-Whitney } U \text { tests } \\ \mu m & \text { Microns (mm }{ }^{-3} \text { ) } \\ \text { s/fMyHC } & \text { Slow/fast myosin heavy-chain } \\ \text { 3-D } & \text { immunohistomarker } \\ \text { ROI } & \text { Three-dimensional } \\ & \text { Region-of-interest } \\ \end{array}$

\section{Introduction}

Advancing our knowledge about human body adaptation to microgravity, animal-based research during space missions is clearly needed. Apart from the incompletely understood adaptation and plasticity changes of, for example, skeletal muscle to weightlessness (Adams et al. 2003; Boonyarom and Inui 2006) or spaceflight effects on weightbearing bone
(Turner 2000) the biological effects of microgravity on the genome, proteome, transcriptome, or metabolome are completely unknown (Glass 2003; Jackman and Kandarian 2004; Ventadour and Attaix 2006). Identification of, and search for, the anticipated gravity-sensor(s) or gravity-dependent cellular and molecular mechanism are therefore challenging tasks in future animal research in Space Life Sciences.

A number of genetically engineered mouse models are available to date for use in biomedical research on ground (Austin et al. 2004; Vitali and Clarke 2004). However, only few rodents (mainly rats) were up to now used for studies on orbit (Morey-Holton et al. 2007). Owing to the obvious constraints of spaceflight specialised rodent housing systems including automated survival and environmental controlling devices hosting larger numbers of mice with adequate animal maintenance during microgravity exposure have to be developed and tested by various methods in a ground-based prototypical animal habitat prior to its scientific application in real spaceflight, for example, on biosatellites (Ilyin 2000) or on the International Space Station (Sharpe et al. 2001).

With the development of genetically modified mouse models, an extending attention has been recently given to the housing conditions. Zhu et al. 2006 and Wolfes et al. 2004 were urged because environmental variables can produce behavioural or physiological modifications that can mask, or give false hypothesis, about alterations induced by gene modifications. For example, it is well known that housing conditions may have important effects on the behavioural phenotype of mice (Broom 2006). Likewise, cage enrichment has been shown to alter emotional and cognitive aspects (Iso et al. 2007; Leggio et al. 2005; Wolfer et al. 2004; van Praag et al. 2000). Cage size reduction, however, was found to be preferable to increased cage size (Fullwood et al. 1998). Likewise, cage size reduction could well be detrimental to mouse physiology or even structure of the weightbearing musculoskeletal system thus a minimal floor surface has been proposed by the Guide for the Care and Use of Laboratory Animals (National Research Council 1996). A difficulty with housing mice therefore is to find a compromise between the need of mice for comfortable places and a safe and clean housing device (Baumans et al. 2002; Hoglund and Renstrom 2001; Renstrom et al. 2001; Kallnik et al. 2007; Krohn et al. 2003). The problem becomes particularly acute with animal research in Space when the cages must meet the highly constraining requirements (i.e., space limitations) imposed on microgravity environments. However, as possibly also holds true for animals housed in more unique, i.e., nonstandard area cages in many research laboratories (Baumans et al. 2002; Baumans 2005a, b), housing in special cages with smaller floor size designed for spaceflight (with automated life support and maintenance system) may likely 
affect biological measures other than those induced by the microgravity environment itself and thus may interfere with the specific aims of a microgravity study.

In a ground-based protocol, we tested a mouse science reference module (MSRM1) as a prototype for later application as a "Mice in Space" (MIS) habitat. Our intention was to principally test (1) if the anatomical, physiological and behavioural status of the animals were profoundly altered or modified, and whether (2) the MIS cage environment itself did not induce changes inconsistent with experimental research requirements in space (microgravity or $\mu \mathrm{G}$ ) and comparability with ground-based control conditions on Earth (1G). More specific aims were to investigate whether (1) mice housed in the reduced area MIS cages for up to 25 days (that is the supposed maximum duration of a biosatellite space flight) developed any significant effects on weightbearing skeletal muscle and bone, (2) behaviour or (3) stress that might compromise the interpretation of microgravity-induced following exposure during short- and mid-term spaceflight.

Thus, beyond the scope of evaluating a unique housing system developed for space missions, the experimental protocols described in the present paper also addresses several major aspects of cage environments and their possible adverse outcome particularly on the structure and physiology, e.g., weighbearing muscle and bone architecture, behaviour and stress in wild-type C57BL/6 mice, that provide indispensable baseline data sets which may be of more general impact on future experimental scenarios investigating the molecular to systems level comparing either wild-type or genetically modified mice used in research laboratories (Bateson 2005; Broom 1988).

\section{Materials and methods}

Animals and housing conditions

A total of 72 male young adult C57BL/6JRj mice (3-4 month of age, approximately $30 \pm 3 \mathrm{~g}$ b.wt., Charles River, France) were preadapted for 7 days in standardsized individually ventilated cages (IVC, Sealsafe ${ }^{\mathrm{TM}}$ model 1284L, Tecniplast Inc., Europe) with saw dust embedding in a rodent animal facility (Katholieke Universiteit Leuven, Belgium), and afterwards randomly assigned by pairs to the following cages and housing conditions with food and water ad libitum and $12 \mathrm{~h}$ light/dark cycle for 25 days: standard individual ventilated cage (IVC, $310 \times 150 \mathrm{~mm}$ floor area, volume $5.8 \mathrm{l}$ ), reduced area standard cage (IVCR, $180 \times 100 \mathrm{~mm}$ floor area, volume 2.25 1), i.e., a grid wall was adjusted to standard IVC cages to reduce floor area, and three newly designed climatized cages referred to as MIS [184 × $100 \mathrm{~mm}$ floor area comparable to the IVCR cages, volume 1.51 (w/o grid separator) and 0.771 (with grid separator)], as integral part of a MSRM1 (mouse science reference module) prototypical device produced by Alcatel Alenia Space Inc. (Milano, Italy). All cages were fixed in a Sealsafe-Rack ${ }^{\mathrm{TM}}$ (Tecniplast Inc.) with individually ventilated cages (IVC) by a multiconnected climatic system supply (air in and out filtered at $0.2 \mu)$. See Supplement 1 for more details.

\section{Food and water supply}

The food delivery system at the rear side of MIS cages consisted of two separate food bar cartridges $(120 \times 80 \times$ $9 \mathrm{~mm}$ ) with a mass of $85 \mathrm{~g}$ each that allowed a mean food consumption of $5 \mathrm{~g} /$ day for two animals [food bar composition: humidity $12 \%$, proteins $18.5 \%$, fat $3.0 \%$, fibres $6.0 \%$, vitamins, i.e., vit. A (14.4 UI/kg), D3 (1.26 UI/kg), E (49.5 mg/kg), and folic acid (1.92 mg/kg), and a mineral mix including Fe (180 mg/kg), Mn (54 mg/kg), Zn (67.5 mg/ $\mathrm{kg}), \mathrm{Cu}(11.7 \mathrm{mg} / \mathrm{kg})$ and I $(0.9 \mathrm{mg} / \mathrm{kg})]$. The food bars were connected to a spring support system, a long screw, and a turning knob and entered the cages at about $50 \mathrm{~mm}$ from the floor to reduce contamination. Animals in IVC and IVCR cages had access to food pellets of identical composition as the food bars of MIS cages. The water delivery system consisted of two standard $100 \mathrm{ml}$ plastic water bottles connected to a commercially available stem activated valve (model A160 Edstrom) on top of the MIS cages. The assembly was inserted to the air inlet plenum so that filling and measuring of water could be performed without opening the cages to reduce possible stress. IVC and IVCR cages were equipped with the same assembly to allow accommodation of animals to this special water delivery system.

Air conditioning and temperature

A constant air flow of $0.004 \mathrm{~m} / \mathrm{s}$ was used for IVC and IVCR cages (top to front flow direction, equivalent to $0.27 \mathrm{~m}^{3} / \mathrm{h}$ exchange volume), and a slightly higher air flow of $0.2 \mathrm{~m} / \mathrm{s}$ (top to bottom direction, equivalent to $13.2 \mathrm{~m}^{3} / \mathrm{h}$ ) necessary to force all disposals (mainly faeces and urine) into the waste filter at the cage bottom was applied to the MIS cages to mimic flight maintenance conditions. The constant temperature and relative humidity $(\mathrm{RH})$ setpoints were $23 \pm 0.3^{\circ} \mathrm{C}$ and $50 \% \mathrm{RH}$ for both MIS and IVC cages. A more detailed description of the technical support of the automated life support system of the MIS device including all technical measures is published elsewhere (Silva et al. 2008).

Experimental design

Animals in MIS cages were always housed in pairs [separated by grid wall (MISg group, $n=16$ ) or not (MIS 
group, $n=10)$ ] in the course of four successive trials (1-4) with principally two basic protocols (cf. Supplement 1).

Video acquisition and technical support

During experiments, all cages were subjected to $24 \mathrm{~h}$ video control using a PC, a video sequencer WebDynCast and a MultiTasker Video Switch connected to a digital camera (Sunkwang SK-1004X, resolution $640 \times 480$ pixels). Data were recorded on an external hard disk (I-Omega). These data were used for the technical assessment, control of animal welfare (e.g., activity control) and maintenance only (Silva et al. 2008).

\section{Tissue sampling}

For muscle and bone analysis, all animals of the MISg group of Trial $2(n=6)$ and a comparable number from the control groups (IVC, IVCR group, each $n=6$ ) were sacrificed after the end of the 25 days housing period, respectively. One animal pair of the MIS group (without grid wall) denoted as "T" (tissue) of Trial 4 (cf. experimental design Supplement 1) was additionally used for behavioural tests for statistical reasons (see below). From animals of the MISg group, the calf soleus muscle ( $m$. soleus) was dissected and shockfrozen in liquid nitrogen, and stored at $-80^{\circ} \mathrm{C}$.

\section{Immunohistochemistry}

Cryosections ( $8 \mu \mathrm{m}$ diameter) from frozen muscle samples were mounted on protein-coated slides (SuperFrostPlus, Menzel-Gläser Inc., Germany), air-dried, and prepared according to the following staining protocols: Primary antibodies: (1) anti-dystrophin (1:50 dilution, overnight at $4^{\circ} \mathrm{C}$, www.scbt.com), (2) anti-slow-type myosin heavy chain (sMyHC, 1:500 dilution, $1 \mathrm{~h}$ at room temperature, RT, www.sigma-aldrich.com), (3) anti-fast type (fMyHC, 1:500 dilution, $1 \mathrm{~h}$ at RT, www.sigma-aldrich.com). Secondary detection antibodies ALEXA 488 (green fluorescence) and/or ALEXA 555 (red fluorescence), were diluted 1:2,000 in incubation buffer and incubated for $1 \mathrm{~h}$ at RT (www.invitrogen.com). Coded and immunolabelled sections were inspected and analysed with a three channel high-resolution confocal microscope (Leica TCS SP-2, Leica Microsystems, Germany) as previously published (Rudnick et al. 2004).

Myofibre size and type distribution

We measured the cross-sectional area (CSA) in individual groups of type I and type II myofibres (250 myofibres each) in soleus cryosections from each animal/group ( $n=5$ or $n=6$ ) identified by immunohistochemistry using the Leica image analysis software (www.leica-microsystems.com). The CSA represented the area $\left(\mu \mathrm{m}^{2}\right)$ in a circle positioned by the cursor over perpendicularly cut immunostained myofibre I and II profiles (the sarcolemma marker dystrophin delineated the cell borders) and the slow/fast MyHC immunostaining identified slow versus fast type myofibres in soleus muscle (McGuigan et al. 2002). A total of 250 myofibre profiles were analysed from each soleus per animal $(n=5)$ of each group. All images were digitized under identical confocal image resolution and setting conditions. Percent values of all housing conditions are presented in a box plot for comparison. We counted individual groups of slow myofibres type I (green fluorescent) and fast myofibres type II (red fluorescent) using doubleimmunohistochemical staining (slow and fast $\mathrm{MyHC}$, in total 250 myofibres) per soleus muscle from each animal/ group ( $n=5$ or $n=6$ ). Myofibres showing both markers (yellow-greenish colour in merged images, i.e., hybrid fibres) were excluded. Values are given as percent changes versus pre-values (set as zero baseline) and represent relative rather than absolute changes of myofibre type distribution in the soleus muscle. Quantitative determination of myofibre phenotype distribution in mice was performed as previously described (Rudnick et al. 2004).

Bone 3-D microarchitecture and reconstruction

For bone analysis, the femur, parietal bone (calvaria) and lumbar spine were excised from the same sacrificed IVC $(n=5)$, IVCR, and MISg mice ( $n=6$, each), rinsed in $0.9 \%$ saline and immersed in $3.7 \%$ paraformaldehyde fixative followed by acetone dehydration. Afterwards, samples were air-dried for $1 \mathrm{~h}$, and vertically fixed by glue or plastyline on the rotating platform of the micro-CT devices and microscanned as given below. Owing to organisational constraints (i.e., available time slots) bone samples were analysed at three different European Synchrotron facilities (TOMCAT, SYRMED, and BM05, cf. Supplement 2).

\section{Bone mineralisation}

The reconstructed grey levels of the micro-CT images were related to the degree of mineralisation in bone by using a theoretical relationship validated with experimental data (Nuzzo et al. 2002). To calibrate mineral content, different phantoms media were used for each synchrotron facility; i.e., distilled water for TOMCAT-PSI and SYRMEP-ELETTRA, and glass for BM05-ESRF. The degree of mineralisation is represented by the volume bone density $\left(\mathrm{mgHA} / \mathrm{cm}^{3}\right)$ and was calculated using the following equation:

$\rho_{\mathrm{TrB}}=\frac{\rho_{\mathrm{HA}} \times \mu_{\mathrm{TrB}}}{\mu_{\mathrm{HA}}}$ 
$\rho_{\mathrm{HA}}$ is the hydroxylapatite (HA) nominal density " $3,140 \mathrm{mg} / \mathrm{cm}^{3} ; \mu_{\mathrm{HA}}$ is the HA linear absorption coefficient at the specific measurement beam energy $(\mathrm{keV}) ; \mu_{\operatorname{TrB}}$ is the trabecular bone linear absorption coefficient at the specific measurement beam energy $(\mathrm{keV}) ; \rho_{\operatorname{TrB}}$ is the trabecular bone density ( $\mathrm{mg} \mathrm{HA} / \mathrm{cm}^{3}$ ) parameterized to HA. No prior assumption of bone geometry was made (Hildebrand and Rüegsegger 1997).

Collection of faecal samples and corticosterone metabolite analysis

The faeces voided during a $24 \mathrm{~h}$ period was collected from the MIS cages at days $1,8,16$, and 24 by carefully removing the bottom waste filter drawer where the faeces accumulated during housing without disturbing the mice in the cage partitions above (cf. Supplement 1). Sampling of faeces from all 12 MIS cages (Trials 1-4) at all four time points was sometimes impaired by unusual excrement sedimentation (i.e., urine, faeces, crumbs) of waste filters resulting in variable $n$ numbers. In parallel, 24-h faecal samples were also collected on days 1, 8, 16, and 24 from the bottom of the IVC and IVCR cages using forceps. All samples were coded and stored frozen at $-20^{\circ} \mathrm{C}$ for corticosterone metabolite (CM) analysis.

For statistical reasons, the faecal samples were pooled from each housing condition and analysed for immunoreactive corticosterone metabolites (CM) using a 5alphapregnane-3beta,11beta,21-triol-20-one enzyme-immunoassay (EIA). Details regarding development, biochemical characteristics, and biological validation of this assay are described by Touma et al. (2003, 2004). Before EIA analysis the faecal samples were homogenised and aliquots of $0.05 \mathrm{~g}$ were extracted with $1 \mathrm{ml}$ of $80 \%$ methanol. A detailed description of the assay performance has been published elsewhere (Touma et al. 2003). The intra- and interassay coefficients of variation were 9.1 and $14.0 \%$, respectively.

\section{Behavioural analysis}

Following different cage confinements, animals denoted as " $\mathrm{B}$ " and one pair denoted as " $\mathrm{T}$ " (cf. protocol overview Supplement 1) held under MIS housing conditions (MISg, $n=8$; MIS, $n=8+2$ ) as well as comparable numbers of animals from the control groups (IVC, IVCR, each $n=8$ ) were subjected to an intense regimen of behavioural tests. In particular, we tested the responsive changes related to motor performance, anxiety, learning/memory, as well as aggressiveness (cf. detailed test configurations, Supplement 3). All behavioural tests were carried out over a period of about 2 weeks (post-experimental phase) with the following order to prevent stressing tests that may bias the outcome of the successive tests: grip strength, rotarod, open field, L/D box, elevated plus-maze, Porsolt forced swimming, passive avoidance test, spontaneous alternation task, activity cage, and dyadic encounters. Each mouse was transported to the experimental room one hour before the experiment. The test set-up was rinsed and cleaned-up after each mouse. Mice were isolated for $24 \mathrm{~h}$ before the dyadic encounters. The mice were weighed on the first and last day of testing. Cage activity was recorded by an activity logger using infrared photo beams (D'Hooge et al. 2005). The T-maze test was made as previously described (Gerlai 1998).

\section{Statistical analysis}

As a normal distribution of data could not always be assumed, most of the analyses (except repeated ANOVA to examine body weight measures) were performed using non-parametric statistics (Siegel and Castellan 1988). Statistical differences in the three different housing systems were calculated with the KWH test. In case of significant variation proved by the KWH test, post hoc comparisons between the groups were done using multiple MannWhitney $U$ tests (MWU test). Here, significance levels were corrected according to the sequential Bonferroni (Bf) technique. All tests were applied two-tailed and were calculated using the software package SPSS (version 12.0.1). ANOVA on ranks (Friedman test) was used to evaluate significant changes of $\mathrm{CM}$ concentrations over time during the 25 days of housing in MIS, IVC-R and IVC cages, respectively. For all tests, differences were considered significant if their probability of occurring by chance was less than $5 \%(P<0.05)$.

\section{Results}

\section{Body weight}

In all groups, the body weight was stable over the period of testing and no intergroup difference occurred at the end of the testing session (day effect $P=0.17$; group effect $P=0.49$, interaction $=0.06$, repeated measures ANOVA). During the experiment or thereafter, animals of either housing conditions revealed no major changes in their body weight, food and water uptake as compared to initial values before start of the experiment (Table 1).

\section{Skeletal muscle}

We analysed the soleus muscle which is a weightbearing mainly slow-type skeletal muscle of the hindlimb (calf) with a well-known structure and fibre type composition (slow vs. fast) that is highly susceptible to inactivity or extended mechanical unloading situations. Immunohistochemistry 
Table 1 Overview of water uptake ( $\mathrm{ml} /$ day), food uptake ( $\mathrm{g} /$ day) and body weight ( $\Delta \%$ b.wt. in $\mathrm{g}$ ) between first and last day of animal cage confinement

\begin{tabular}{lllc}
\hline Group $/ n$ & Water uptake & Food uptake & $\begin{array}{l}\Delta \% \text { b.wt. } \\
(\mathrm{g})\end{array}$ \\
\hline MISg/14 & $8.3 \mathrm{ml} /$ mouse per day & $4.8 \mathrm{~g} /$ mouse per day & -1.27 \\
MIS/10 & $5.7 \mathrm{ml} /$ mouse per day & $4.2 \mathrm{~g} /$ mouse per day & -6.67 \\
IVC/12 & $4.8 \mathrm{ml} /$ mouse per day & $3.7 \mathrm{~g} /$ mouse per day & 1.45 \\
IVCR/12 & $4.6 \mathrm{ml} /$ mouse per day & $3.6 \mathrm{~g} /$ mouse per day & 2.80 \\
\hline
\end{tabular}

$M I S g$ two animals per cage separated by grid wall, MIS two animals per cage without grid wall, $I V C$ normal area cage mice (animal pairs), IVCR 50\% reduced area cage mice (animal pairs). Pooled data analysis from each group

and confocal morphometrical analysis were used in order to see if mice housed in the MIS cages would show any changes in the soleus histomorphology (myofiber size) and phenotype (slow vs. fast myofibre pattern) thus reflecting altered postural/motor performance activity due to the special housing conditions.

Double immunostaining with slow MyHC (marker of slow-twitch type I fibres) and dystrophin (cell membrane border marker) was used to measure the myofibre crosssectional area (CSA in $\mu \mathrm{m}^{2}$ ) of perpendicularly cut soleus myofibres (Fig. 1a). The averaged relative CSA of myofibres I was always larger (approx. $900-1.100 \mu \mathrm{m}^{2}$ ) than the CSA of the myofibres II (approx. $700-850 \mu \mathrm{m}^{2}$ ) in all groups (Fig. 1b). Comparison between groups (KWH test, $d f=2$ ); however, showed unchanged CSA of both myofibres I and II in either IVC, IVCR or MIS cage groups (Fig. 1b).

Quantification of the myofibre type I (green immunosignals) and II (red immunosignals) distribution was performed in merged image sets from each soleus muscle and cage group, with the hybrid fibres showing yellow pixel signals $(<3-5 \%$ on average) omitted from analysis (Fig. 2). No significant changes in the relative amounts of myofibre types I and II were determined in solei from either of the groups suggesting an overall preservation of the normal myofibre type distribution and an obvious lack of skeletal muscle atrophy in weightbearing solei muscles of the MIS group as compared with IVC or IVCR groups. However, the amount of myofibres type I in IVCR animals was small suggesting a trend towards a slow-to-fast myofibre type specific change in that animal group compared to IVC or MIS group (Fig. 2b).

Bone 3-D quantification of trabecular microarchitecture and mineralisation

Bone architecture and mineralisation are two important components that may be considerably altered due to extended hypokinesia as, for example, induced by nonstandard cages with smaller floor size. Taking advantage of three synchrotron X-ray sources, the 3-D bone microarchitecture of weightbearing bone (femur, tibia and lumbar spine) and non-weightbearing bone (calvaria) was investigated at high spatial resolutions ranging from 0.7 to $9 \mu \mathrm{m}$ (Fig. 3). We first reconstructed images of femurs to verify whether different set-ups of the beam lines imposed a significant difference in the final results. The obtained microarchitecture parameters for femurs of all groups (MIS, IVCR, or IVC) were very similar with the exception of the $X$ and $Y$ values obtained by the SYRMEP-ELETTRA (Supplement 2). This difference is probably due to the limited resolution $(9 \mu \mathrm{m})$ used at the SYRMEP that did not permit the same precision for estimating structures such as $\mathrm{TbTh}$ and trabecular porosity. The trabecular porosity normally has a dimension ranging from 3 to $8 \mu \mathrm{m}$ (Fig. 3). Such small pores were not detectable with the SYRMEPELETTRA device and mathematically could have lowered the experimental absorption coefficient $\left(\mu_{\exp }\right)$. For comparison, the mean values of femur and lumbar spine trabecular microarchitectural parameters measured by micro-CT of MISg animals are listed (Table 2, Supplement 2). Significant differences were not found in our measures of weightbearing femurs and lumbar spines between the different cage groups using three different facility sources.

\section{Bone mineralisation}

The unique characteristics of the micro-CT setups (monochromatic beam, high photon flux, high signal-to-noise ratio and parallel beam) allowed us to use the high spatial resolution images for quantitative evaluation of the mineral content of weightbearing (femur, spine) and non-weightbearing bones (parietal bone, calvaria) (Fig. 4). The mean representative distributions of the degree of trabecular mineralisation were assessed by (1) the addition of the numbers of occurrences of each degree of mineralisation and (2) by normalisation of the total number of events. Despite of the different facility set-ups, the obtained degree of mineralisation for all bone types of either groups (IVC, IVCR or MIS) corresponded to the experimental internal error $\left( \pm 100 \mathrm{mgHA} / \mathrm{cm}^{3}\right)$. As for the bone microarchitecture, significant differences in bone mineralisation between mice of different cage groups were not found (Fig. 4).

\section{Corticosterone metabolites}

Analysis of the corticosterone metabolites (CM) in faeces was used as a non-invasive method to monitor stress during animal housing under non-standard conditions such as in reduced area cages (IVCR, MIS) as compared to standard area cages (IVC). Animals of the IVCR as well as the IVC group showed no significant variation in $\mathrm{CM}$ concentration that was observed between days 1-24 of the total 25 days 
Fig. 1 Determination of the cross-sectional area (CSA) in mouse soleus following IVC, IVCR and MIS housing. a Confocal images showing immunofluorescence double staining of soleus muscle fibres with the slow MyHC marker (myofibres I, green) and the membrane marker dystrophin (red). b Statistical analysis of cross-sectional area (CSA) of soleus myofibre type I and II of MIS, IVCR and IVC mice. Data are given as box plots showing medians (lines in the boxes), 25 and $75 \%$ percentiles (boxes) as well as 10 and $90 \%$ percentiles (whiskers). No significant changes were determined in the CSA of slowtype (I) or fast type (II) myofibres between either groups. IVC group $(n=5)$, IVCR $=50 \%$ reduced area cage group $(n=5), M I S$ 'Mice in Space' group $(n=5)$. KWH test, $d f=2$; $C S A$ crosssectional area $\left(\mu \mathrm{m}^{2}\right)$, Bar $100 \mu \mathrm{m}(\mathbf{a})$
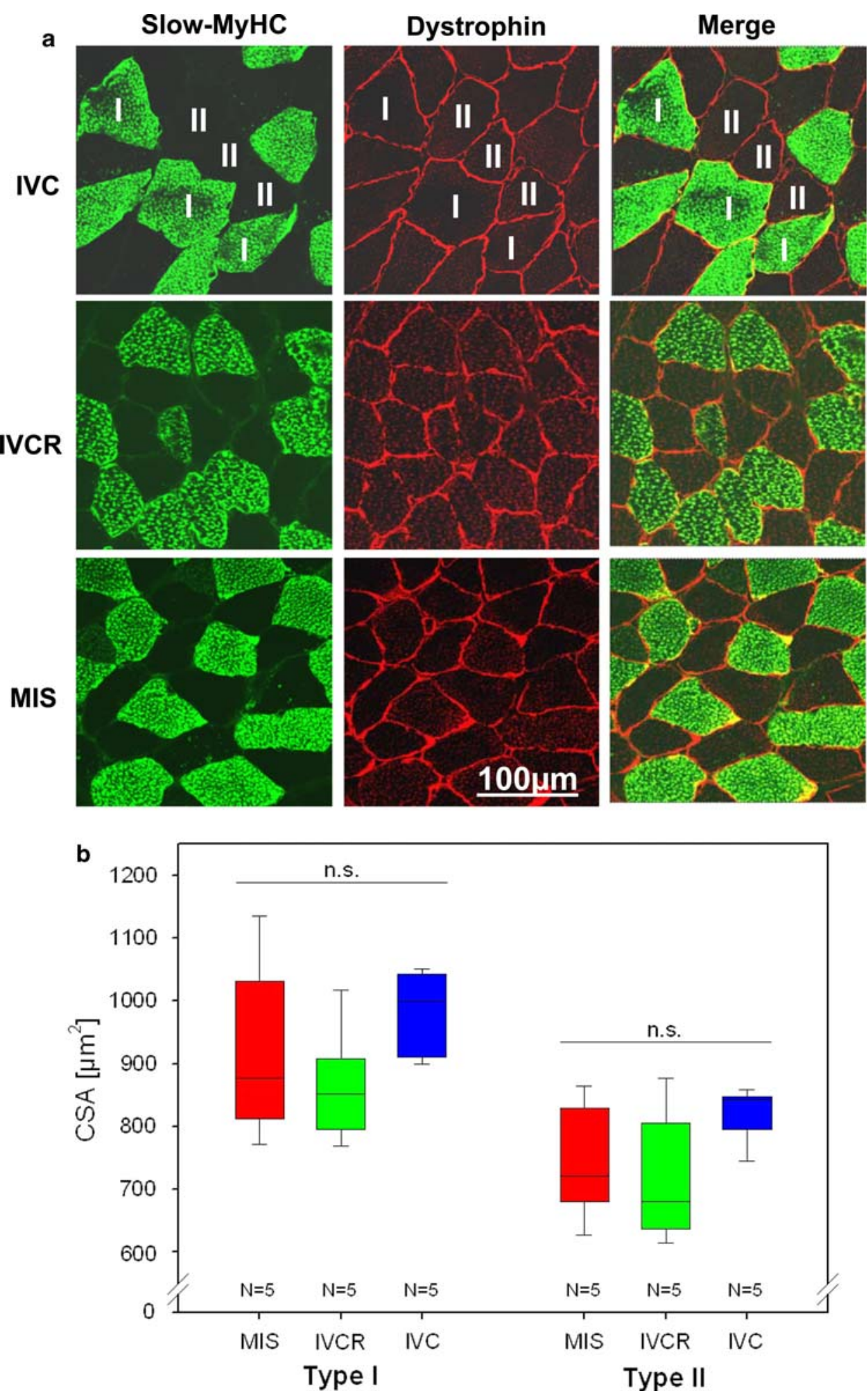

housing period (Friedman test, $N_{\mathrm{IVCR}}=8, N_{\mathrm{IVC}}=10$, $\chi_{\mathrm{r}}^{2}=2.55$ and 2.21, $d f=3, P=0.466$ and $P=0.530$ ). Mean CM concentrations ranged about 35-45 ng/0.05 g faeces in both groups (Fig. 5). Although animals housed in the MIS cages showed a significant variation of $\mathrm{CM}$ concentrations over time (Friedman test, $N_{\mathrm{MIS}}=7$, $\left.\chi_{\mathrm{r}}^{2}=10.04, d f=3, P=0.018\right)$. Comparisons between the three housing conditions revealed significant differences only on day 1 of MIS housing (KWH test, day $1: \chi_{\mathrm{r}}^{2}=7.77$, $d f=2, P=0.021$; see Fig. 5). Here, post hoc analyses proved that MIS-housed mice had significantly higher CM concentrations (mean: $59.4 \mathrm{ng} / 0.05 \mathrm{~g}$ faeces) than mice 
Fig. 2 Determination of myofibre type I versus II distribution in mouse soleus muscle following various housing conditions. a upper panel Confocal images of double immunostaining for slow-type myofibres (I) with anti-slow MyHC antibody (green), and for fast type myofibres (II) with anti-fast MyHC antibody (red) in mouse soleus muscle from the IVC group. a lower panel Some fibres showing both markers (asterisks red and

green $=$ yellow in merged images) denoted as hybrid or transition fibres were excluded from quantification.

b Quantification of myofibre type I and type II pattern in soleus muscle of age-matched animals of IVC, IVCR, and MIS group. No significant changes in myofibre type ratio were present between groups $(P>0.05)$.

IVC group $(n=5)$;

IVCR $=50 \%$ reduced area cage group $(n=5)$; MIS 'Mice in Space' group (MISg, $n=5$ ), Bar $100 \mu \mathrm{m}$ (a)
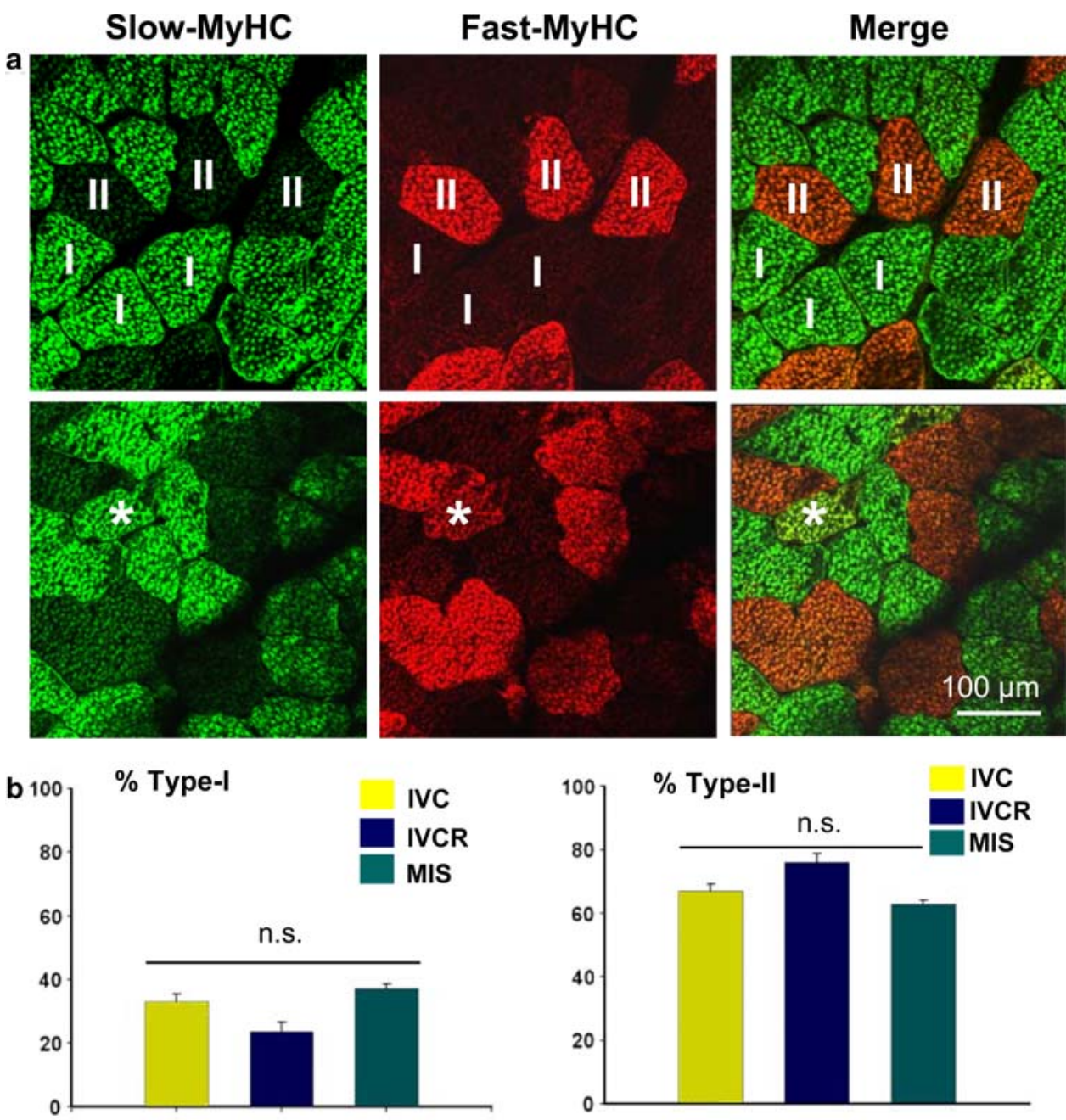

housed in the other two confinement cages, respectively (MWU tests, MIS vs. IVC: $U=15$, Bf corrected $P=0.048$; MIS vs. IVC: $U=14$, Bf corrected $P=0.033$; IVCR vs. IVC: $U=40, \mathrm{Bf}$ corrected $P=0.683$; see Fig. 5). Nevertheless, such differences were no longer detectable in faeces pooled from MIS-housed animals at other time increments (days 8-16-24) (KWH tests, day 8, 16 and 24: $\chi^{2}=1.24-4.47, d f=2$, all $P>0.1$; see Fig. 5).

\section{Behaviour}

In the present investigation, we used various test protocols monitoring the fundamental aspects of behaviour, i.e., motor performance, anxiety, learning/memory as well as aggressiveness, following different housing conditions that are listed for comparison (Table 3). Data from the MIS cage groups (MISg, $n=8$; MIS, $n=10$ ) were pooled as no significant group differences were found after separate analysis.

Motor performance (Grip test, Rotarod, Table 3): all groups performed similarly well on the Rotarod motor balance test $(P=0.507)$, and did not show any difference in the daily rhythm or the quantity of movement in the activity cage suggesting no major changes in their overall performance activity. However, significant difference was found in the fore limb muscular force $(P=0.029$, KWH test) by the grip test. The effect was related to a lower force in the MIS group $(P<0.05$, IVC and IVCR, MWU test). On the other hand, the intergroup difference was not confirmed when considering the force exerted by the four legs together $(P=0.22)$.

Anxiety (L/D box, EPM, Porsolt forced swim test, Table 3): all groups increased their number of transitions between the light and dark compartment of the L/D box from the first to the second $5 \mathrm{~min}$ period of observation $(P<0.0001)$. There was an overall intergroup difference $(P=0.032)$. The group difference was not significant during the first $5 \min (P=0.19)$, but MIS mice performed significantly more transitions during the second period $(P=0.005)$. The time in the light zone decreased in all groups, accordingly with increased visits to the dark box, however, comparisons between groups did not show significant changes $(P=0.172)$, as was the case with the 

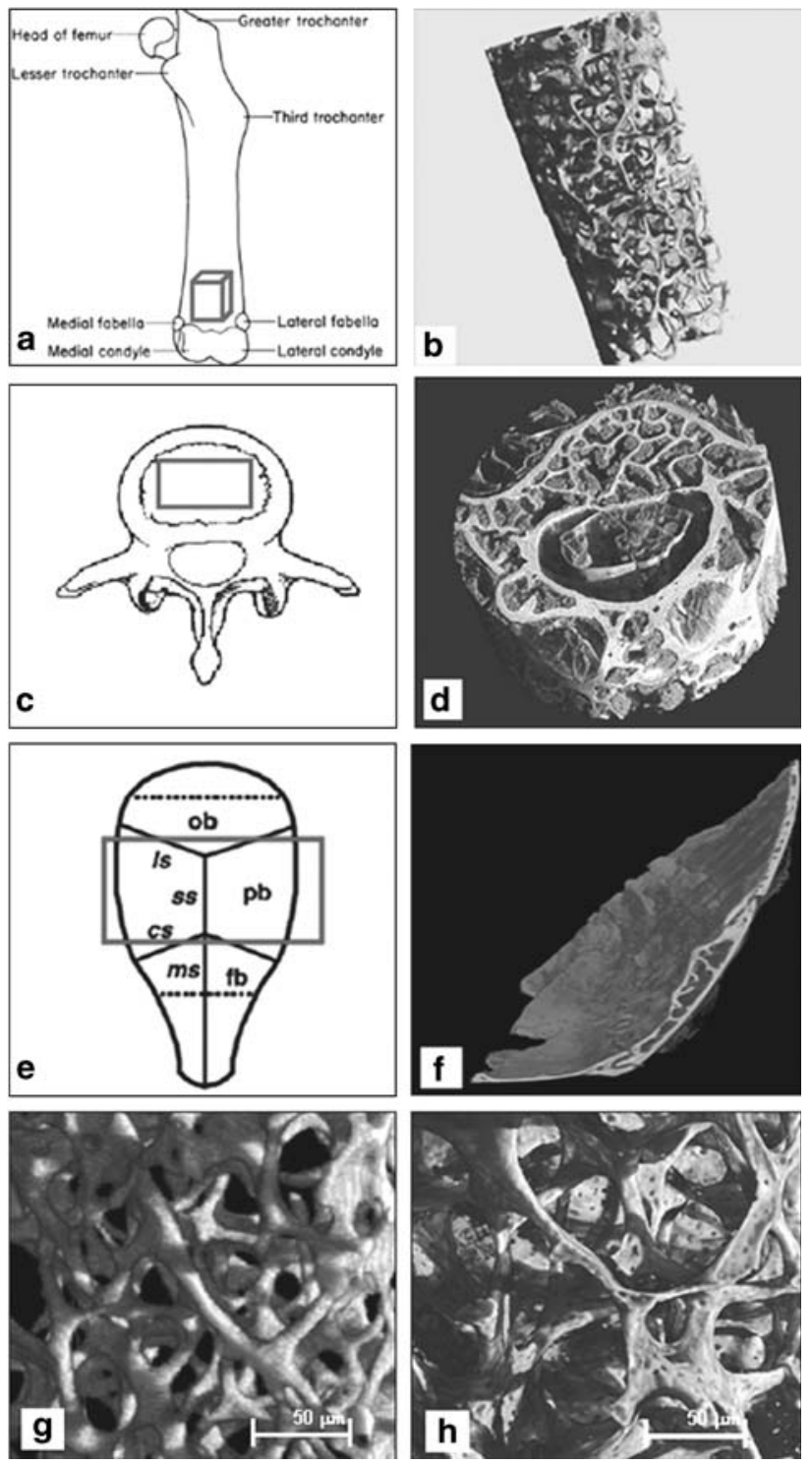

Fig. 3 Bone 3-D microarchitecture analysis performed by synchrotron micro-computed tomography $(\mu \mathrm{CT})$. The regions of interests (ROIs) are indicated in red cubes in lefthand panels (a) femur, (c) lumbar spine, and (e) parietal bone. The reconstructed 3-D images are shown in righthand panels (b), (d), and (f). $\mathbf{g}-\mathbf{h}$ Reconstructed 3-D images of femurs showing low resolution $(>9 \mu \mathrm{m})$ of the trabecular pores by the ELETTRA-SYRMEP (g), and higher resolution $(<5-8 \mu \mathrm{m})$ of trabecular pores by the ESRF-BM05 (h)

frequency of rearing either in the light or dark box. In the EPM tests, MIS-housed animals did not show any difference in the time spent or the number of visits to the various corridor arms (either in absolute or relative frequency). All three groups revealed similar reactions to the Porsolt forced swim test. The absence of difference in the EPM test in MIS animals may exclude anxiety level differences.

Exploration (open field test, Table 3): animals of all groups visited the various zones of the open field similarly, as shown by the absence of difference in the duration of
Table 2 Trabecular 3-D microarchitectural parameters for femur and lumbar spine of mice following different cage conditions

\begin{tabular}{|c|c|c|c|c|c|c|c|c|}
\hline \multirow[t]{2}{*}{ Parameters } & \multicolumn{4}{|c|}{ Femur } & \multicolumn{4}{|c|}{ Lumbar Spine } \\
\hline & MIS & IVCR & IVC & SD & MIS & IVCR & IVC & SD \\
\hline $\mathrm{BS} / \mathrm{BV}\left(\mathrm{mm}^{-1}\right)^{\mathrm{a}}$ & 136 & 155 & 137 & 11 & 128 & 130 & 129 & 1 \\
\hline$X$ & 140 & 160 & 144 & 11 & 139 & 140 & 150 & 6 \\
\hline$Y$ & 143 & 162 & 144 & 11 & 147 & 153 & 144 & 5 \\
\hline$Z$ & 124 & 141 & 120 & 11 & 99 & 97 & 93 & 3 \\
\hline $\mathrm{BV} / \mathrm{TV}(\%)^{\mathrm{b}}$ & 13 & 13 & 13 & 0 & 15 & 16 & 14 & 1 \\
\hline $\operatorname{TbTh}(\mu \mathrm{m})^{\mathrm{c}}$ & 15 & 14 & 15 & 1 & 16 & 16 & 16 & 0 \\
\hline$X$ & 15 & 13 & 14 & 1 & 15 & 14 & 14 & 1 \\
\hline$Y$ & 14 & 13 & 14 & 1 & 14 & 14 & 14 & 0 \\
\hline$Z$ & 17 & 15 & 17 & 1 & 21 & 20 & 22 & 1 \\
\hline $\operatorname{TbN}\left(\mathrm{mm}^{-1}\right)^{\mathrm{d}}$ & 9 & 9 & 9 & 0 & 9 & 12 & 9 & 2 \\
\hline$X$ & 9 & 10 & 10 & 1 & 10 & 14 & 10 & 2 \\
\hline$Y$ & 9 & 10 & 9 & 1 & 10 & 13 & 10 & 2 \\
\hline$Z$ & 8 & 9 & 8 & 1 & 7 & 9 & 6 & 2 \\
\hline $\operatorname{TbSp}(\mu \mathrm{m})^{\mathrm{e}}$ & 102 & 96 & 99 & 3 & 107 & 102 & 102 & 3 \\
\hline$X$ & 102 & 92 & 96 & 5 & 97 & 84 & 88 & 7 \\
\hline$Y$ & 98 & 92 & 94 & 3 & 94 & 93 & 91 & 2 \\
\hline$Z$ & 110 & 105 & 113 & 4 & 144 & 129 & 143 & 8 \\
\hline
\end{tabular}

$I V C$ control (normal area) cage group, IVCR 50\% reduced area control cage group, MIS "Mice in Space" cage group, $S D$ standard deviation

${ }^{\text {a }}$ Bone surface to bone volume $(\mathrm{BS} / \mathrm{BV}) \times \mathrm{mm}^{-1}$

${ }^{\mathrm{b}}$ Bone volume to total tissue volume (BV/TV) in percent $(\%)$

c Trabecular thickness ( $\mathrm{TbTh})$ in microns $(\mu \mathrm{m})$

d Trabecular numbers $(\mathrm{TbN}) \times \mathrm{mm}^{-1}$

e Trabecular separation $(\mathrm{TbSp})$ in microns $(\mu \mathrm{m})$

presence in the various zones. On the other hand, there was an overall tendency for the MIS group to be more active as shown by the total distance moved $(P=0.053)$, the frequency of moving $(P=0.028)$ and the frequency of rearing $(P=0.04)$ in the arena of the test device (i.e., increased activity in the peripheral or intermediate zones $(P=0.03 ; 0.03 ; 0.005$, for distance moved, frequency of moving and rearing, respectively), but not in the centre area $(P=0.36 ; 0.11 ; 0.33$ for distance moved, frequency of moving and rearing, respectively). The absence of difference in the use of the centre area therefore suggest that also here the differences observed in MIS-housed animals may result from an increased motor behaviour rather than a change in anxiety levels.

Learning and memory (learning avoidance test, T-maze alternation, Table 3): the three animal groups did not differ in the avoidance learning test $(\mathrm{P}=0.186)$. They showed a stable level of alternation in the T-maze over the 2 days of testing. There was an overall group effect $(P=0.041)$, due to a lower spontaneous alternation in the IVC and IVCR groups, whereas the rate of alternation in MIS was 
Fig. 4 Bar graph showing bone mineral density measurements compared between three different synchrotron devices. The dark grey/red (ELETTRASYRMED), light grey/green (PSI-TOMCAT), and black/blue bars (ESRF-BM05) represent mineral density values $\left(\mathrm{mg} \mathrm{HA} / \mathrm{cm}^{3}\right)$ of mice femurs, lumbar spines and parietal bones obtained from animals housed for 25 days in MIS (MISg), IVCR and IVC cages. The values represent means \pm standard errors (SD)
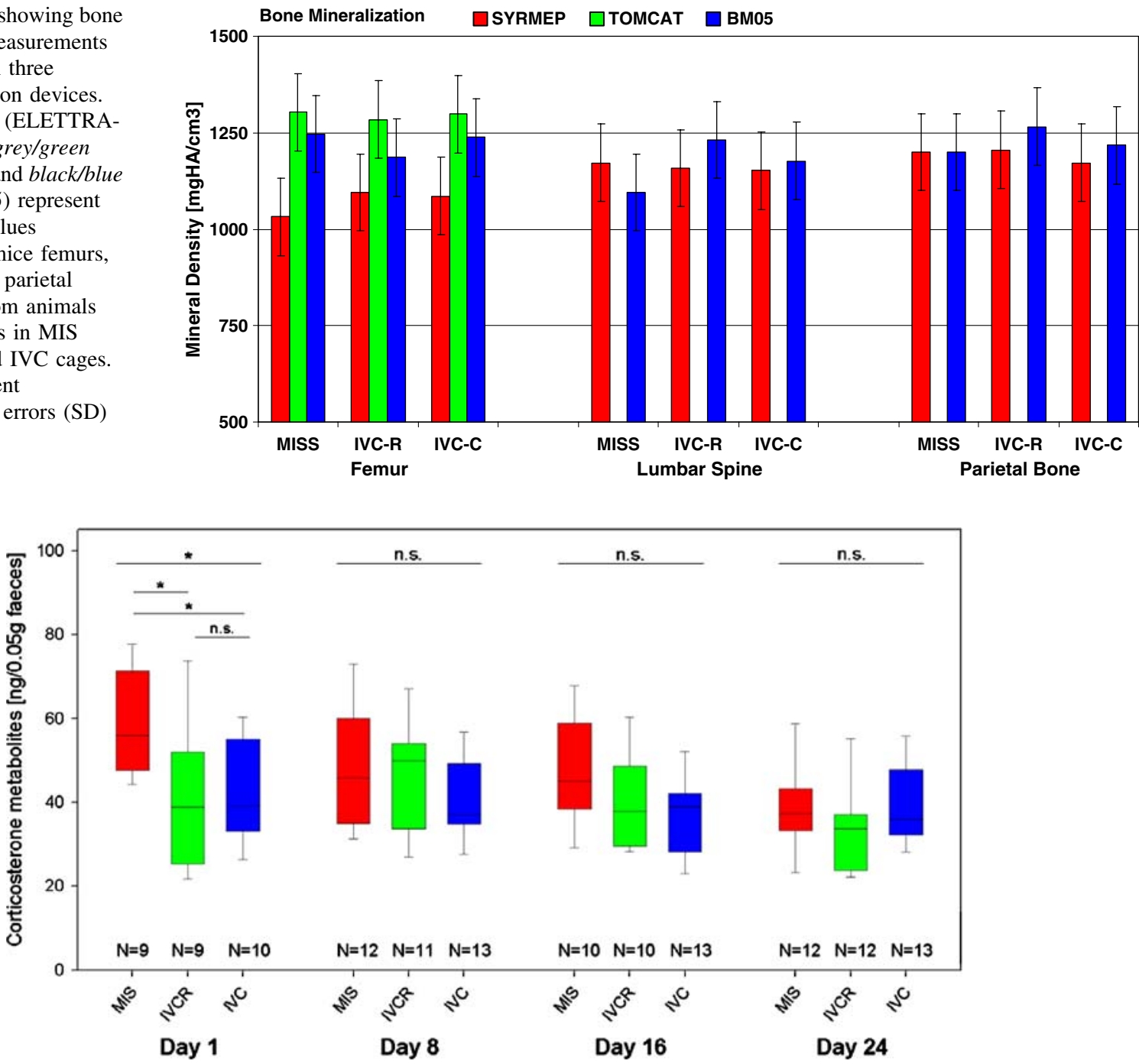

Fig. 5 Time course (day 1-8-16-24) of faecal corticosterone metabolite (CM) concentrations in collected faeces of mice kept in the MIS (red), IVCR (green), and the IVC (blue) housing system, respectively. Data are given as box plots showing medians (lines in the boxes), 25 and $75 \%$ percentiles (boxes) as well as 10 and $90 \%$ percentiles

consistent with the measures commonly obtained in mice housed in standardised cages.

Aggressiveness (Table 3): the frequency of offensive, defensive and self comfort behaviours were recorded during dyadic encounters and compared with either MIS, IVC or IVCR mice. Thus, during encounters the MIS mice showed more frequent offensive $(P=0.003)$ and self comfort behaviours $(P=0.001)$ as compared to IVC or IVCR mice encounters.

\section{Discussion}

Space flight experimentation with sufficient numbers of small rodents (mice) is a necessary prerequisite for a better (whiskers). The variable $n$ numbers are due to unusual waste filter sedimentation that sometimes impaired the collection of faeces material from MIS cages. Statistically significant differences between the groups (KWH test and post hoc MWU tests) are indicated by asterisks $\left(P>0.1\right.$ n.s., $P<0.05^{*}$; for details see text $)$

understanding of the still incompletely understood gravitational input on the vertebrate body system on Earth and for investigation of the microgravity-induced body changes or risk assessment of long distance Space explorations with human astronauts in future missions (Moon, Mars). The technical constraints of spaceflight, such as payload and energetic needs, impose strong limitations in the life support design, e.g., in terms of floor size and impoverished environment of animal housing systems designed for spaceflight. These limitations are likely susceptible to affect animal physiology or behaviour and need to be investigated in more details. The use of special housing systems in real spaceflight might produce artefacts in several biological measures that may likely be generated by the unique animal habitat rather than by microgravity itself thus mimicking false 
Table 3 Overview of behavioural tests with IVC, IVCR and MIS groups

\begin{tabular}{|c|c|c|c|c|c|c|c|c|c|}
\hline \multirow[t]{2}{*}{ Behavioural test } & \multirow[t]{2}{*}{ Parameter measured } & \multicolumn{2}{|l|}{ IVC } & \multicolumn{2}{|l|}{ IVCR } & \multicolumn{2}{|l|}{ MIS } & \multicolumn{2}{|c|}{ Group comparison } \\
\hline & & Median & Ranges & Median & Ranges & Median & Ranges & $H$ & $P$ \\
\hline \multirow[t]{2}{*}{ Grip strength test } & Fore limb normalised peak force & 24.96 & $24-27$ & 24.42 & $23-29$ & 22.59 & $19-23$ & 7.08 & $0.029 *$ \\
\hline & Hind limb normalised peak force & 29.73 & $29-32$ & 29.92 & $29-31$ & 29.12 & $28-29$ & 3.01 & $0.221 \mathrm{n} . \mathrm{s}$ \\
\hline \multirow[t]{2}{*}{ Rotarod test } & Latency to fall (s) & 187 & $144-216$ & 161 & $115-185$ & 149.5 & $123-235$ & 1.36 & $0.507 \mathrm{n} . \mathrm{s}$ \\
\hline & Number of transitions & 4 & $1-9$ & 6 & $2.5-8$ & 10.5 & $8.5-12.5$ & 6.83 & $0.032 *$ \\
\hline \multirow[t]{3}{*}{ L/D Box test } & Time in light zone (s) & 413.4 & $355-504$ & 386.6 & $312-519$ & 331.5 & 291-390 & 3.52 & 0.17 n.s. \\
\hline & Rearing Frequency (Light) & 32 & $22.6-35$ & 19 & $12-26.5$ & 24 & $15-27$ & 0.79 & 0.6n.s. \\
\hline & Rearing Frequency (Dark) & 12 & $1.5-17$ & 12 & $0-15.5$ & 19.5 & $15-27$ & 0.6393 & $0.97 \mathrm{n} . \mathrm{s}$. \\
\hline \multirow[t]{7}{*}{ Elevated plus-maze test } & Time in the open arms & 18 & $8.5-42$ & 36 & $26-51$ & 26 & $18.5-39$ & 3.52 & 0.171 n.s. \\
\hline & Time in the closed arms & 536 & $508-561$ & 522 & $497-547$ & 529 & $510-534$ & 1.08 & 0.578 n.s. \\
\hline & Time in the central area & 36.5 & $29.5-45$ & 38 & $29-55$ & 40.5 & $34.5-63$ & 0.69 & $0.708 \mathrm{n} . \mathrm{s}$. \\
\hline & No. entries (open arms) & 2.5 & $1.5-4.5$ & 3 & $3-5.5$ & 3 & $2-3.5$ & 3.01 & $0.221 \mathrm{n} . \mathrm{s}$ \\
\hline & No. entries (closed arms) & 23.5 & $22-28$ & 24 & $17-30$ & 25.5 & $22-29$ & 0.15 & 0.926 n.s. \\
\hline & No. entries (central area) & 26 & $24-30$ & 27 & $19-33$ & 27.5 & $24-31$ & 0.14 & 0.934n.s. \\
\hline & $\%$ entries (open arms) & 4.39 & $2.9-7.2$ & 7.6 & $6.4-8.1$ & 5.8 & $3.6-8.1$ & 4.635 & $0.098 \mathrm{n} . \mathrm{s}$. \\
\hline Forced swim test & Total swimming time (s) & 162 & $151-211$ & 193 & $158-217$ & 137 & 101.-161 & 4.39 & 0.111 n.s. \\
\hline \multirow[t]{4}{*}{ Open-field test } & Total distance travelled (m) & 30.18 & $22-39$ & 27.09 & $24-29$ & 36.12 & $31-41$ & 5.8 & 0.053 \\
\hline & Time in inner zone (s) & 21 & $11-56$ & 18.4 & $13-24$ & 30.6 & $22.3-56.6$ & 2.26 & 0.323 n.s. \\
\hline & Time in outer zone (s) & 409.6 & $286 .-473$ & 434.8 & $383-459$ & 331.1 & $294-356$ & 3.77 & 0.152 n.s. \\
\hline & Number of rearings & 28 & $21-48$ & 37 & $16-44.5$ & 54 & $44-83$ & 6.39 & $0.04 *$ \\
\hline Learning avoidance test & Latency to enter (s) & 61 & $40-283$ & 132 & $69-300$ & 62 & $33-148$ & 3.36 & 0.186n.s. \\
\hline T-maze alternation & Frequency of alternation & 7 & $6-8.5$ & 6 & $4.5-8$ & 8.5 & $7.5-11$ & 6.38 & $0.041 *$ \\
\hline \multirow[t]{3}{*}{ Aggressiveness } & Number of offensive acts & 19 & $8-37$ & 16 & $10-26$ & 39 & $19-66$ & 11.29 & $0.003 *$ \\
\hline & Number of defensive acts & 7.5 & $3-15$ & 7 & $3-9$ & 6.5 & $2-20$ & 0.74 & 0.69n.s. \\
\hline & Number of comfort acts & 57 & $44-85$ & 71 & $47-84$ & 98 & $70-133$ & 18.34 & $0.001 *$ \\
\hline
\end{tabular}

Group statistics show the median and the extrema $25-75 \%$ percentiles

Group comparisons are calculated using the Kruskal-Wallis $H$ test (KWH test), IVC standard area cage group $(n=12), I V C R 50 \%$ reduced area cage group $(n=12), M I S$ "Mice in Space" cage groups $(n=16+2), P$ level of significance

positive or negative results which may clearly interfere with the scientific outcome. In order to investigate and compare both expected as well as unexpected limitations in the scientific evaluation of structural and physiological measures of C57 wild-type mice housed in small cages such as those designed for, e.g., microgravity research, animals housed in three prototypical MIS cages with fully controlled life support technology were compared with age-matched male animals housed in parallel in standard area IVC and/or reduced area IVCR cages connected to a custom made climatic system. The $\mathrm{C} 57 \mathrm{Bl} / 6$ mouse strain provides one basis for several genetically modified mouse models including transgenic and knock-out mice in many laboratories (Austin et al. 2004; Kallnik et al. 2007) that also may be used for future experimentation on biosatellites. Similar scenarios of multidisciplinary research protocols designed for the present study provide the ultimate basis for Space Life Sciences Research in terms of, e.g., "ground-based" controls on Earth for future spaceflight missions using biosatellites or the ESA Columbus docking module of the ISS (since 2007).
In the present study, particular attention was given to the structure and morphology of the weightbearing bones and skeletal muscles, which are highly susceptible to prolonged inactivity (hypokinesia) in area-restricted environments (small cages) or, more importantly, following mechanically unloading in microgravity environments. An important finding was that housing mice in the MIS cages for 25 days did not show any significant effects neither on weightbearing bone quality, nor on lower limb soleus muscle structure and size compared to control housing in IVC cages. The effects of the cage size on skeletal muscle was controlled by comparing standard IVC with IVCR cages whose surface floor was downsized from $233 \mathrm{~cm}^{2}$ to $90 \mathrm{~cm}^{2}$ by a grid wall. Animals housed in IVCR cages tended to show an altered slow-type I versus fast type II myofibre distribution pattern in their solei muscles compared to IVC. However, this was not observed if IVC and the MIS animals (housed with half the area of the IVCR cages) were compared. So far, we can only speculate about a possible decrease in slow-type myofibres I (i.e., 
anti-gravity or slow-twitch myofibres) observed in the IVCR group as compared to the IVC group which may have become significant in this group over time (i.e., $>25$ days). Fibre transitions (type I $>$ II) due to muscle inactivity have been frequently observed in animal models and humans following muscle denervation, immobilisation or spaceflight and is a well-know remodelling mechanisms in disused vs. active skeletal muscle (Fitts et al. 2001; Adams et al. 2003; Harrison et al. 2003; Blottner et al. 2006). More recently, fibre transition (type II > type I) has been documented following repeated electrical impulses imposed on a skeletal muscle (Shen et al. 2006). Video control studies performed in our study (M. Silva, personal communication) revealed that mice housed in the IVCR tended to be less active during the 25 days housing period than those housed in normal area IVC cages (i.e., more area $=$ more activity $>$ myofibre maintenance). Therefore, hypokinesia with less muscle activity (=more remodelling) may be one possible explanation for an ongoing change in myofibre type I versus II distribution observed in the soleus muscle of IVCR versus IVC mice following 25 days housing in the reduced area IVCR cages, similar to microgravity (Caiozzo et al. 1996).

Although the IVCR and IVC mice did not show significant differences in their water and food uptake, the mice of the IVCR cages tended to increase their body weight at the end of each trial possibly due to hypokinesia. Alternatively, the MIS mice may simply be more active while manipulating ("playing") the unique food bar supply (which can be reached by a narrow rim to sit or jump on rear up the wall), or the water uptake system inserted from the top of the MIS cages very similar to housing supplementation conditions. Paradoxically, this could constitute an 'enriched environment' and may well have influenced animal performance and behaviour as well as physiological parameters suggested previously (Benefiel et al. 2005). As already discussed, this could likely prevent atrophy or remodelling changes of myofibre types in MIS mice thereby maintaining a normal-like muscle fibre size and distribution pattern of slow versus fast myofibre types in soleus muscle. Similar unusual adaptation mechanisms to the cage environments may well be observable during spaceflight (e.g., floating versus active body performance) and should be taken into consideration, in particular, for multidisciplinary animal research proposals using a habitat for small rodents in future spaceflights.

Furthermore, stress physiological aspects measured by a non-invasive highly sensitive corticosterone metabolite determination as well as fundamental behavioural aspects were also considered that might reflect some of the animal's perception during extended confinement and should be routinely monitored in terms of maintenance in normal animal facilities as well as in animal spaceflight.
Compared with IVCR animals, the MIS mice showed a relatively higher physical activity in the open field and the L/D box tests (cf. Table 3). This is consistent with findings from $24 \mathrm{~h}$ video acquisition performed in the MIS cage housing system that was possibly due to some avoidance behaviour because of an uncomfortable internal air flow (i.e., $0.1-0.3 \mathrm{~m} / \mathrm{s}$ in MIS vs. $0.004-0.007 \mathrm{~m} / \mathrm{s}$ in IVC) or temperature conditions (i.e., mice in MIS cages avoided to stay in the air flow from the central outlet above which may result in a much lower "perceived" temperature than the actually controlled $23 \pm 0.3^{\circ} \mathrm{C}$ temperature (Silva et al. personal communication). Given the fact of an altered physical activity in individually housed animals, we cannot exclude the possibility that due to the unique cage environment the MIS animals may have counteracted muscle atrophy by more physical activity that was obviously missing, e.g., in animals held in reduced IVCR cages which tended to show altered myofibre morphology of their solei muscle.

On the behavioural level no major differences were found between the three different housing conditions (cf. Table 3). This holds true for virtually all behavioural domains tested in the present study. Whether the increased activity of the MIS-housed mice measured in the postexperimental phase was related to a higher basal activity level or to a more pronounced curiosity of these mice (e.g., more social investigation) remains an open question. Compared with IVCR mice, MIS mice appeared more "aggressive" in our test battery. This may be an example of cage structure counteracting cage size. This effect may be explained by the fact that the MIS cages could have generated a chronic mild stress that is known to induce depression and irritability (Cryan and Mombereau 2004; Mineur et al. 2003; Willner 2005). This hypothesis was not consistent, however, with regular stress measures made in the cages during the 25 days (i.e., day 1, 8, 16 and 24) housing period.

Aggressiveness in laboratory cages is modulated by cage enrichment and cage size, and it is commonly agreed that reduced surface prevents the output of territorial behaviour and leads to a decrease in aggression (Smith and Corrow 2005; Van Loo et al. 2001). We thus presume that similar mechanisms contributed to inhibit aggressiveness in IVCR cages. Despite of these two differences, animals from the IVC and IVCR groups revealed similar behavioural patterns suggesting that both "control" groups either housed in reduced IVCR or standard area size IVC cages may serve as controls for the MIS animal group at least for the parameters measured in the present study. Our findings are consistent with previous reports that showed that the cage size can be decreased by almost $50 \%$ of the normally recommended size $\left(77 \mathrm{~cm}^{2}\right)$ proposed by the Animal Guide without negative effects 
(Fullwood et al. 1998; Smith et al. 2005, 2004). Increased aggressiveness could also result form the fact that animals perceived the MIS cage as an 'enriched environment' as already mentioned above. The influence of enrichment on aggressiveness appears to show some ambiguity. Some types of enrichments may decrease, while others may rather increase aggressiveness (cf. Van Loo et al. 2001). Nevertheless, the higher frequency of offensive behaviours during the pairs encounters, in addition to the increased comfort behaviours could be a consequence of an increased contact frequency due to the higher physical activity (or simply more social compliance) in MIS mice rather than the result of an increased aggressive behaviour (Van Loo et al. 2003).

The non-invasive analyses of corticosterone metabolite (CM) concentrations (faeces) revealed that only on day 1 (immediately after transferring the animals to the MIS cages) slightly elevated CM concentrations were clearly detected, but were no longer detectable at the following sampling increments on day 8, 16 and 24, indicating a novelty-induced effect and proving a rather quick adaptation to the new housing environment. Furthermore, the elevation of stress hormone levels seen on day 1 in the MIS animals was still within the range of the normal diurnal variation of CM concentrations described for mice held in animal facilities (Dallmann et al. 2006; Touma et al. 2004; Voigtlander et al. 2006). These results clearly showed that housing laboratory mice in the MIS cage system was, after a short habituation period, not stressful per se compared to the conventional housing conditions in IVC cages. The higher food uptake observed in the animal pairs of the MISg cages (with a grid wall) might be due to competition, as often can be observed in nature when two individuals were put together. Though, it remains possible, that mice underwent 25 days of chronic exposition to a low stress that did not generate an increase in corticoid levels. Previous studies showed a strong impact of chronic mild stress on depression, with aggressiveness as a comorbidity factor (Bardgett et al. 1994; Bats et al. 2001; Willner 2005), but this does not necessarily induce an increase in corticotropin-releasing factor (Swiergiel et al. 2003). The present findings confirm that, at least for limited durations, mice may satisfy a floor surface much smaller than the minimal surface (National Research Council 1996) without significant changes of their physiological indices as proposed earlier (Fullwood et al. 1998; Smith et al. 2005, 2004). We also propose a protocol including preadaptation of mice to MIS cages as part of a ground-based replica of the actual flight module. The preadapted mice ("astromice") could then be transferred even together with their individual MIS cage environment as complementary part of a MIS flight module destined for a real spaceflight before launching on site.

\section{Study drawbacks}

Concerning muscle and bone parameters, a bias may still exist not to reveal possible differences between groups due to the small sample size $(n=5-6)$. However, significant changes were not detected by confocal analyses and highresolution micro-CT imaging thus making significant changes of muscle and bone morphology induced by MIS housing unlikely. It remains an open question whether our battery of behaviour measures may be too stressful per se, or partly be the result of the animal re-accomodation to normal IVC cages during the post-experimental test phase rather than the result of the experimental housing conditions in IVCR or MIS cages. As pair housing will be the preferred protocol for later application of MIS (i.e., always two mice per MIS cage, either separated or not) in real spaceflight, possible effects of single housing (e.g., one mouse per MIS cage) on stress or behaviour following variable cage confinements were not evaluated. In real microgravity both the MIS cage size and volume will be virtually increased, i.e., from 2-D to 3-D, as microgravity exposed "astromice" are challenged by more "floor area" (e.g., cage walls) than at 1 $\mathrm{G}$ (mostly one floor area used). In real spaceflight, an ultimate control would be to have "astromice" housed in a 1:1 MIS cage replica fixed to a short-arm centrifuge device simulating $1 \mathrm{G}$ (Earth gravity) during microgravity exposure on orbit. For logical reasons, ground-based testing of the MSRM1 (MIS) device did not include such controls.

\section{Conclusion}

The presented multidisciplinary biological measures provide compelling evidence that the MIS habitat will not, on its own, produce significant effects on mice that could confound interpretations of differences induced by other factors, such as conditions in Space. The MIS cage device therefore provides a good opportunity for an automated life support system for adequate mouse maintenance in spaceflight, allowing reliable multidisciplinary scientific inflight data recordings during short and medium-term spaceflights as well as postflight cellular and molecular analysis of various organs and tissues of wild-type versus genetically modified mouse models exposed to real microgravity on, e.g., biosatellites (BION) which, undoubtedly, would provide the most exciting final proof of our hypothesis in the near future. Apart from the more specialised field of microgravity research, the present findings should help to design future multidisciplinary protocols including unique housing conditions using wild-type or genetically modified mice for broader applications in many laboratories working in the fields of, e.g., neuromusculoskeletal research, neuroendocrinology, behaviour or neuroscience. 
Acknowledgments All experiments were in accordance with the European Community (EC) standards regarding the care and use of laboratory animals. The entire experimental protocols were approved by the Belgium Ethics Commitee (authorisation no. P06119, Ministère de l'Agriculture, Belgium). We thank the European Space Agency (ESA) and Jean-Francois Gaubert and Peter Schiller from ESA-ESTEC Noordwijk, The Netherlands, for financial support and helpful discussion, Chiara Tanconi and Giancarlo Falcetti from Alcatel Alenia Space Inc. Milano, Italy, for providing a prototype of the MIS technical device, and Rudi d'Hooge from the Psychology Department, Biological Psychology, Katholieke Universiteit Leuven, Belgium, for laboratory support and discussions. The technical help of Gudrun Schiffl, Berlin, is appreciated.

\section{References}

Adams GR, Caiozzo VJ, Baldwin KM (2003) Skeletal muscle unweighting: spaceflight and ground based models. J Appl Physiol 95:2185-2201

Austin CP et al (2004) The knockout mouse project. Nat Genet $36: 1132$

Bateson P (2005) The return of the whole organism. J Biosci 30:31-39

Bardgett ME, Taylor GT, Csernansky JG, Newcomer JW, Nock B (1994) Chronic corticosterone treatment impairs spontaneous alternation behaviour in rats. Behav Neural Biol 61:186-190

Bats S, Thoumas JL, Lordi B, Tonon MC, Lalonde R, Caston J (2001) The effects of a mild stressor on spontaneous alternation in mice. Behav Brain Res 118:11-15

Baumans V, Schlingmann F, Vonck M, van Lith HA (2002) Individually ventilated cages: beneficial for mice and men? Contemp Top Lab Anim Sci 41:13-19

Baumans V (2005a) Science-based assessment of animal welfare: laboratory animals. Rev Sci Technol 24:503-513

Baumans V (2005b) Environmental enrichment for laboratory rodents and rabbits: requirements of rodents, rabbits, and research. ILAR J 46:162-170

Benefiel AC, Dong WK, Greenough WT (2005) Mandatory "enriched" housing of laboratory animals: the need for evidence based evaluation. ILAR J 46:95-105

Blottner D, Salanova M, Püttmann B et al (2006) Human skeletal muscle structure and function preserved by vibration muscle exercise following 55 days of bed rest. Eur J Appl Physiol 97:261-271

Boonyarom O, Inui K (2006) Atrophy and hypertrophy of skeletal muscles: structural and functional aspects. Acta Physiol 188: $77-89$

Broom DM (1988) The scientific assessment of animal welfare. Appl Anim Behav Sci 20:5-19

Broom DM (2006) Adaptation. Berl Münch Tierarztl Wochenschr 119:1-6

Caiozzo V, Haddad F, Backer M et al (1996) Microgravity induced fibre switch. J Appl Physiol 81:123-132

Corbetta S, D’Adamo P, Gualdoni S, Braschi C, Berardi N, de Curtis I (in press) Hyperactivity and novelty-induced hyperreactivity in mice lacking Rac3. Behav Brain Res

Cryan JF, Mombereau C (2004) In search of a depressed mouse: utility of models for studying depression-related behaviour in genetically modified mice. Mol Psychiatry 9:326-357

D'Hooge R, Lullmann-Rauch R, Beckers T, Balschun D, Schwake M, Reiss K, von Figura K, Saftig P (2005) Neurocognitive and psychotiform behavioural alterations and enhanced hippocampal long-term potentiation in transgenic mice displaying neuropathological features of human alpha-mannosidosis. J Neurosci 25:6539-6549
Dallmann R, Touma C, Palme R, Albrecht U, Steinlechner S (2006) Impaired daily glucocorticoid rhythm in Per1 (Brd) mice. J Comp Physiol A Neuroethol Sens Neural Behav Physiol 192:769-775

ESA-MSRM Final Presentation, 20 April 2007 (multiple FST member authors) ESA Internal Document

Fitts RH, Riley DR, Widrick JJ (2001) Functional and structural adaptations of skeletal muscle to microgravity. J Exp Biol 204:3201-3208

Fullwood S, Hicks TA, Brown JC, Norman RL, McGlone JJ (1998) Floor space needs for laboratory mice: C56BL/6 males in solidbottom cages with bedding. ILAR J 39:29-36

Glass DJ (2003) Molecular mechanisms modulating muscle mass. Trends Mol Med 9(8):344-350

Gerlai R (1998) A new continuous alternation task in T-maze detects hippocampal dysfunction in mice. A strain comparison and lesion study. Behav Brain Res 95:91-101

Gerlai R, Pisacane P, Erickson S (2000) Heregulin, but not ErbB2 or ErbB3, heterozygous mutant mice exhibit hyperactivity in multiple behavioural tasks. Behav Brain Res 109:219-227

Harrison B, Allen D, Girten B et al (2003) Skeletal muscle adaptations to microgravity exposure in the mouse. J Appl Physiol 95:2462-2470

Hildebrand T, Rüegsegger P (1997) A new method for the modelindependent assessment of thickness in three-dimensional images. J Microsc 185:67-75

Hoglund AU, Renstrom A (2001) Evaluation of individually ventilated cage systems for laboratory rodents: cage environment and animal health aspects. Lab Anim 35:51-57

Ilyin EA (2000) Historical overview of the BION Project. J Gravitational Physiol 7:S1-S8

Iso H, Simoda S, Matsuyama T (2007) Environmental change during postnatal development alters behaviour, cognitions and neurogenesis of mice. Behav Brain Res 179:90-98

Jackman RW, Kandarian SC (2004) The molecular basis of skeletal muscle atrophy. Am J Physiol Cell Physiol 287:C834-C843

Kallnik M, Elvert R, Ehrhardt N, Kissling D, Mahabir E, Welzl G, Faus-Kessler T, de Angelis M, Wurst W, Schmidt J, Hölter S (2007) Impact of IVC housing on emotionality and fear learning in male $\mathrm{C} 3 \mathrm{HeB} / \mathrm{FeJ}$ and $\mathrm{C} 57 \mathrm{BL} / 6 \mathrm{~J}$ mice. Mamm Genome 18:173-186

Krohn TC, Hansen AK, Dragsted N (2003) The impact of cage ventilation on rats housed in IVC systems. Lab Anim 37(2):85-93

Leggio MG, Mandolesi L, Federico F, Spirito F, Ricci B, Gelfo F, Petrosini L (2005) Environmental enrichment promotes improved spatial abilities and enhanced dendritic growth in the rat. Behav Brain Res 163:78-90

McGuigan MR, Kraemer WJ, Deschenes MR et al (2002) Statistical analysis of fibre area in human skeletal muscle. Can J Appl Physiol 27:415-422

Mineur YS, Prasol DJ, Belzung C, Crusio WE (2003) Agonistic behaviour and unpredictable chronic mild stress in mice. Behav Genet 33:513-519

Morey-Holton ER, Hill EL, Souza KA (2007) Animals and spaceflight: from survival to understanding. J Musculoskeletal Neuronal Interact 7:17-25

National Research Council NRC (1996) Guide for the care and use of laboratory animals. Washington DC, National Academy Press, p 124

Nuzzo S, Peyrin F, Cloetens P, Baruchel J, Boivin G (2002) Quantification of the degree of mineralization of bone in three dimensions using synchrotron radiation microtomography. Med Phys 29:2672-2681

Renstrom A, Bjoring G, Hoglund AU (2001) Evaluation of individually ventilated cage systems for laboratory rodents: occupational health aspects. Lab Anim 35:42-50 
Rudnick J, Püttmann B, Tesch P et al (2004) Differential expression of nitric oxide synthases (NOS 1-3) in human skeletal muscle following exercise countermeasure during 12 weeks of bed rest. FASEB J 18:1228-1230

Sharpe A, Vellinger J, Ainsworth M et al (2001) The advanced animal habitat centrifuge (AAH-C). In: Proceedings of 31st international conference on environmental systems: ICES, July 9-12, Hilton in the Wlt Disney World Resort, Orlando, FL, Warrendale, Pa, SAE International Paper No. 251-AAA-C

Shen T, Liu Y, Randall WR et al (2006) Parallel mechanisms for resting nucleo-cytoplasmic shuttling and activity dependent translocation provide dual control of transcriptional regulators HDAC and NFAT in skeletal muscle fibre type plasticity. J Muscle Res Cell Motil 27:405-411

Siegel S, Castellan NJ (1988) Non-parametric statistics for the behavioural sciences. McGraw Hill

Silva M, Liu Y, Serradj N, Salanova M, Touma C, Jamou M, Blottner D, Cancedda R, Giuliani A, Rustichelli F, Aerts JM, Vico L, D'Hooge R, Falcetti G, Berckmans D (2008) Mice in Space: technical evaluation of a housing system. J Gravitational Physiol (in press)

Smith AL, Corrow DJ (2005) Modifications to husbandry and housing conditions of laboratory rodents for improved well-being. ILAR J 46:140-147

Smith AL, Mabus SL, Muir C, Woo Y (2005) Effects of housing density and cage floor space on three strains of young adult inbred mice. Comp Med 55:368-376

Smith AL, Mabus SL, Stockwell JD, Muir C (2004) Effects of housing density and cage floor space on C57BL/6 J mice. Comp Med 54:656-663

Swiergiel AH, Leskov IL, Dunn AJ (2008) Effects of chronic and acute stressors and CRF on depression-like behaviour in mice. Behav Brain Res 186:32-40

Touma C, Palme R, Sachser N (2004) Analyzing corticosterone metabolites in faecal samples of mice: a noninvasive technique to monitor stress hormones. Horm Behav 45:10-22
Touma C, Sachser N, Mostl E, Palme R (2003) Effects of sex and time of day on metabolism and excretion of corticosterone in urine and faeces of mice. Gen Comp Endocrinol 130:267-278

Turner RT (2000) Physiology of a microgravity environment. Invited review. What do we know about the effects of spaceflight on bone? J Appl Physiol 89:840-847

Van Loo PL, Mol JA, Koolhaas JM, Van Zutphen BF, Baumans V (2001) Modulation of aggression in male mice: influence of group size and cage size. Physiol Behav 72:675-683

Van Loo PL, Van Zutphen LF, Baumans V (2003) Male management: coping with aggression problems in male laboratory mice. Lab Anim 37(4):300-313

van Praag H, Kempermann G, Gage FH (2000) Neural consequences of environmental enrichment. Nat Rev Neurosci 1:191-198

Vitali R, Clarke S (2004) Improved rotorod performance and hyperactivity in mice deficient in a protein repair methyltransferase. Behav Brain Res 153:129-141

Voigtlander T, Unterberger U, Touma C, Palme R, Polster B, Strohschneider M, Dorner S, Budka H (2006) Prominent corticosteroid disturbance in experimental prion disease. Eur J Neurosci 23:2723-2730

Ventadour S, Attaix D (2006) Mechanisms of skeletal muscle atrophy. Curr Opin Rheumatol 18:631-635

Willner P (2005) Chronic mild stress (CMS) revisited: consistency and behavioural-neurobiological concordance in the effects of CMS. Neuropsychobiology 52:90-110

Wolfer DP, Litvin O, Morf S, Nitsch RM, Lipp HP, Wurbel H (2004) Laboratory animal welfare: cage enrichment and mouse behaviour. Nature 432:821-822

Zhu SW, Yee BK, Nyffeler M, Winblad B, Feldon J, Mohammed AH (2006) Influence of differential housing on emotional behaviour and neurotrophin levels in mice. Behav Brain Res 169:10-20 